\title{
QUESTÕES PARA A HISTÓRIA INTELECTUAL: UMA LEITURA DE GILBERTO FREYRE E O ESTADO NOVO
}

\author{
MESQUITA, Gustavo. Gilberto Freyre e o Estado Novo: região, nação e \\ modernidade. São Paulo: Global, 2018.
}

Bruno Cesar Cursini ${ }^{l}$

O trabalho de Gustavo Mesquita ${ }^{2}$ pode ser entendido como uma busca pelo vocabulário político de uma determinada época. Sua narrativa está alicerçada na perspectiva interdisciplinar da História Social ligada à História dos Conceitos, e sua pesquisa situa-se na oposição da abordagem intelectualista e internalista, recorrendo às categorias elementares da Sociologia para concluir acerca do objeto delimitado, a saber: "intelligentsia", "ideias sociológicas", "uso político das ideias", "negociação de interesses", etc. (MESQUITA, 2018: 20). Ele tenta afastar-se da tradição de história intelectual inaugurada por Arhur Lovejoy (1936-2001), uma tradição, segundo ele, gradualmente incorporada pela historiografia brasileira, e que "insiste em desconsiderar o vínculo de dependência entre a produção das ideias e a dimensão mundana da vida no tempo e no espaço, ou seja, o mundo dos interesses dos agentes coletivos" (MESQUITA, 2018: 20). Uma das saídas que enxergamos para este contextualismo reducionista é a proposta de Dominick LaCapra, que afirma que

\footnotetext{
${ }^{1}$ Possui bacharelado e licenciatura em História pela UNESP de Franca, e mestrado em História pela UFU - Universidade Federal de Uberlândia. Atualmente, cursa doutorado em História Social na USP, sob orientação da professora Camila Grejo. Email:bcursini @ usp.br

${ }^{2}$ Resenha do livro Gilberto Freyre e o Estado Novo: região, nação e modernidade. São Paulo: Global, 2018, de autoria de Gustavo Mesquita, doutor em História Social pela Universidade de São Paulo (2017) e mestre em História pela Universidade Federal de Goiás (2012). Durante o doutoramento, fez estágio sanduíche na Vanderbilt University, Nashville, Estados Unidos, com o propósito de pesquisar em arquivos norte-americanos especializados na história das Ciências Sociais no século XX. Desenvolve pesquisa sobre história contemporânea, com ênfase no pensamento político-social e seus nexos com os direitos humanos e a agenda de antirracismo das organizações internacionais. O livro de Mesquita é uma publicação premiada pelo Concurso Nacional de Ensaios - Prêmio Gilberto Freyre 2016-2017, realizado pela Fundação Gilberto Freyre e pela Global Editora.
} 
que o processo de intepretação dos textos chamados clássicos compreende sua contextualização em diferentes camadas ou dimensões, que ele enumera como sendo seis: a intenção autoral, a vida do autor, a sociedade, a cultura, o corpus bibliográfico do autor e os modos de discurso (disciplinas, áreas do conhecimento, etc.) (LACAPRA, 1998). Mesquita estuda as modificações que a definição e as possibilidades semânticas do verbete "região" sofreram durante a vigência do Estado Novo, e o papel de Gilberto Freyre no processo dessas mudanças de sentido: regionalismo deixaria de ser algo identificado a sectarismo e separatismo, passando a significar a contemporização das diferenças locais; diferenças que, integradas, passariam a compor o nacional. Moema Selma D'Andrea já havia afirmado que

é no sentido de agregar as forças conservadoras que o regionalismo freyreano se aproxima da ideologia nacionalista da coesão, da indiferenciação e da homogeneização. E é por isso que não lhe interessa o conceito separatista para a Região Nordeste. (D’ANDREA, 1992: 91).

A ideia de que o conceito de região passou, no Brasil, por uma profunda reformulação no final das primeiras décadas do século XX, também é posta em debate pelo historiador Durval Muniz de Albuquerque Jr. em A invenção do Nordeste (1999). Como sugere o próprio título deste livro, o enfoque é dado na construção da região Nordeste através de uma série de recursos imagéticos, que suscitaram uma visibilidade e uma dizibilidade específicas, as quais, por seu turno, estavam postas a serviço de diversos interesses, um dos quais seria a captação de recursos públicos federais para subsidiar a oligarquia açucareira decadente, da qual Freyre era um dos porta-vozes.

O escopo da análise de Mesquita está, especificamente, em como a obra e a trajetória de Freyre figuram neste processo. De acordo com ele, o sociólogo pernambucano, devido ao renome que angariou, tornou-se um baluarte da aristocracia açucareira - aristocracia que enfrentava a decadência em face da modernização dos modos de produção e das novas dinâmicas de divisão do trabalho e acumulação de capital - dentro do aparato político e burocrático do Estado Novo, no qual tinha trânsito e influência: Mesquita pesquisa a biografia de Freyre, acompanhando suas atividades políticas, culturais e técnicas neste 
período. Um dos destaques é a participação de Freyre nos quadros do Programa de Restauros do Serviço do Patrimônio Histórico e Artístico Nacional (Sphan), como supervisor. Segundo Mesquita,

O vínculo com essa e outras instituições fundadas pelo regime conferiu-lhe estabilidade financeira, assim como ressonância prática ao projeto regionalista. $\mathrm{O}$ contexto dominante de invenção da "cultura nacional" como negócio oficial era favorável à colaboração entre as partes, havendo, efetivamente, momentos estáveis de parceria com o regime. (MESQUITA, 2018: 111).

Mesquita observa que Freyre não integrava propriamente a "guarda intelectual" do Estado Novo - um regime que teve no campo intelectual uma de suas bases de sustentação - , mas que gozava de um prestígio ímpar, que lhe permitiu incidir diretamente no planejamento estratégico que vinha sendo traçado pelo Estado para a condução da sociedade. "A elite federal era leitora dileta de seus ensaios." (MESQUITA, 2018: 213)

Ainda assim, Freyre teve seus atritos e disputas por poder com agentes do governo. Mesquita dá destaque para as brigas entre Freyre e Agamenon Malgalhães - interventor de Pernambuco que se engajou de forma animada numa "revitalização" do Recife que incluía a destruição dos mocambos da cidade - deslindando o efeito delas na produção de Sobrados e mucambos (1936-2004) e Mocambos do Nordeste (1937). Ele também demonstra como Nordeste (1937) foi um livro quase didático em sua função de transmitir à elite dirigente do Estado Novo uma nova ideia de região, fundada em preceitos ecológicos e humanos, ideia esta que foi, a seguir, implantada pela cartilha oficial do IBGE. São intepretações renovadas e extremamente valiosas para uma compreensão plena destes textos.

Tais ponderações são tentativas de interpretação da intenção autoral, mas são também um olhar para a comunidade leitora. Pode-se dizer que Mesquita produz, não apenas história da leitura, mas também história da recepção das ideias de Freyre pela intelligentsia estado-novista. Há mesmo uma proposta ambiciosa neste sentido, feita no capítulo 2, no qual fica expresso que interessa ao trabalho 
analisar as interações texto contexto para descobrir-se de que modo o conteúdo de Casa-grande \& senzala contribuiu significativamente para a inflexão do regionalismo no curso dos eventos dos anos 1930. Uma mudança conceitual imperativa para o sociólogo, visto que seu tempo não permitia a associação do regionalismo com a prática estadualista da primeira república. (MESQUITA, 2018: 45).

O fato de que os ensaios de Freyre eram lidos pela elite dirigente, inclusive por Vargas, foi o que garantiu a Freyre credibilidade para "integrar os quadros oficiais do IBGE, de modo que, participando das ações do órgão, pôde influir no desenvolvimento dessas ações em busca do conceito de região e de seu nexo com a integração nacional" (MESQUITA, 2018: 129). De acordo com Freyre, o condicionamento da vida humana pelo trópico é o que dá coesão às diversas etnias, tradições culturais, técnicas de produção, relações de trabalho, etc.

De fato, a busca de Freyre por um ethos nacional e a tentativa de aplicar suas teses a toda a extensão do território brasileiro ganham contornos obsessivos à medida que sua obra avança. Sobrados e mucambos (1936-2004) recebeu inúmeros prefácios e acréscimos após sua primeira publicação, boa parte girando em torno de respostas de Freyre às críticas de que suas análises estavam circunscritas apenas a uma parte do Brasil; o Nordeste açucareiro. Sua defesa da diversidade regional não o impedia de defender também um ideal de brasilidade, aplicável a todo o país e com suas raízes em nosso passado colonial. Como diz Moema Selma D’Andrea, Freyre elegeu o passado como genuinamente brasileiro, e o legado do colonizador português como o único influxo cultural imperialista admissível (D’ANDREA, 1992).

$\mathrm{O}$ incomodo de Freyre deve ter aumentado com o andamento do Projeto UNESCO na década de 1950 - do qual Freyre chegou a participar, mas que que ficou, principalmente, sob os auspícios de Arthur Ramos ${ }^{3}$, que negava

\footnotetext{
${ }^{3}$ Ramos assumiu, em 1949, a direção do Departamento de Ciências Sociais da UNESCO, cargo para o qual Freyre fora convidado, mas do qual abrira mão para se dedicar à criação do instituto Joaquim Nabuco. Por sua vez, a direção do Setor de Relações Raciais do Departamento de Ciências Sociais e, portanto, o projeto UNESCO propriamente, ficariam, a partir de 1950, a cargo de Alfred Metraux, antropólogo francês inicialmente simpático às ideias de Freyre. A contribuição do próprio Freyre ao projeto, entretanto, ficaria circunscrita às pesquisas locais no
} 
explicitamente a existência do pretenso ethos nacional: em 1948 Ramos escreve que nossa diversidade impedia que se falasse de um só Brasil, sendo "cedo demais" para indagar-se do "caráter nacional em visões generalizadoras que lancem mão do critério histórico ou social" (RAMOS, 1948: 224).

Foi também o projeto UNESCO que começou a colocar em xeque as ideias de Freyre sobre a existência de uma democracia social e étnica no Brasil. Segundo Mesquita, em 1944, gozando de grande prestígio internacional, Freyre profere uma série de conferências nos Estados Unidos nas quais defende justamente tais ideias polêmicas. Trata-se da coletânea Brazil: an interpretation (1945). Por ser direcionado ao público estrangeiro antes de qualquer outro, este texto nos dá uma dimensão do estrelato de Freyre, da ampla receptividade de que gozava no exterior, vendendo para outros povos a imagem de um Brasil que todos adoravam consumir. Neste livro, encontramos um Freyre simpático à monarquia, cético em relação à "democracia meramente política" num país mestre em "democracia étnica e social", que, embora ainda não estivesse plenamente amadurecida entre nós, estava em vias de aprimorar-se e consolidar-se. A propaganda que ele faz é de uma cultura Brasileira principal, de matriz lusitana, propensa a ser livre de preconceitos raciais, que deve assimilar subculturas como os indígenas, os negros mais africanizados e mesmo colonos de outras nações europeias e asiáticas.

Com uma política democrática ampla como esta - uma política democrática étnica e social -, o Brasil se tornará um país ideal para europeus cansados de estreitos preconceitos de raça e classe, de um nacionalismo iliberal e um sectarismo religioso. ${ }^{4}$ (FREYE, 1945: 119-20)

Já no capítulo 3 de Brazil: an interpretation (1945), o autor vai de encontro ao assunto mais caro à pesquisa de Mesquita: a diversidade regional

Recife. Ver: MAIO, Marcos Chor. O Projeto Unesco e a agenda das ciências sociais no Brasil dos anos 40 e 50. Rev. bras. Ci. Soc., São Paulo, v. 14, n. 41, p. 141-158, out. 1999. Disponível em <http://www.scielo.br/scielo.php?script=sci_arttext\&pid=S010269091999000300009\&lng=en\&nrm=iso $>\quad$ accesso $\quad$ em 11 Sept. 2020. https://doi.org/10.1590/S0102-69091999000300009.

${ }^{4}$ No original: "With a broad democratic policy like this - an ethnically and socially democratic policy - Brazil would become an ideal country for Europeans tired of narrow race and class prejudices and of illiberal nationalism and religious sectarianism." A tradução é nossa, pois não tivemos acesso à Interpretação do Brasil, versão traduzida pelo próprio Freyre em 1947. 
Brasileira e a importância de sua preservação. Freyre atribuí o regionalismo separatista da república velha a uma tentativa canhestra de se copiar o federalismo da constituição norte-americana, mas também critica o que ele chama de "castelanismo": o esforço em se sobrepor uma cultura regional a todas as demais, de forma semelhante ao que fez Felipe II com Castela, na Espanha ( no caso do Brasil, para Freyre a Castela seria a Região Sudeste, com ênfase em Minas Gerais). É neste sentido que faz, inclusive, um apelo direto a Vargas, que seria "um político por demais astuto para desejar ser um novo Felipe II; e hoje em dia há menos reformadores impacientes ou intolerantes com a diversidade regional do que havia há alguns anos" (FREYRE, 1945: 90). Tal apelo deixa bastante evidente que Freyre esperava ser lido por Vargas ou, no mínimo, por alguém de seu círculo mais próximo. Assim Freyre procurava inventar

a identidade de um povo que era visto como mestiço de negro, português e índio, incorporando novos componentes identitários nessa invenção, como o conceito de cultura regional. Era o mito da miscigenação informando e moldando, à sua imagem e semelhança, a invenção da identidade do Brasil moderno. (MESQUITA, 2018: 217).

No quarto capítulo, Mesquita procura entender a relação entre Freyre e alguns outros intelectuais brasileiros. Por exemplo, com José Olympio: ao dirigir a coleção organizada por este editor e chamada "Documentos brasileiros", Freyre "usou estratégias de legitimação do movimento de intelectuais e escritores regionais em defesa do próprio projeto regionalista. Ao prefaciar os livros, tinha nas mãos o controle dos sentidos de sua recepção no interior do público de leitores interessados" (MESQUITA, 2018: 161). Mesquita é levado à algumas reflexões acerca da biografia que Monteiro Lobato e Diogo Melo de Menezes fizeram de Freyre. Biografia, segundo Mesquita, precoce, pois não esperou pela completude da trajetória do biografado. Na verdade, o que os autores queriam era justamente forçar o "processo de envelhecimento social dos livros e ideias regionalistas". (MESQUITA, 2018: 197) Para explicar tal processo, mesquita lança mão de Bourdieu e sua ideia de ilusão biográfica: um acordo entre biografo e 
biografado que seleciona e ordena logicamente acontecimentos específicos, tendo por objetivo a criação de identidades no mundo social (BOURDIEU, 2006). Para demonstrar a existência de tal acordo, Mesquita lembra seu leitor que, em 1943, quando a biografia já contava com o texto pronto, Freyre publicou um artigo no Diário de Pernambuco exaltando a obra de Lobato em decorrência do aniversário de Urupês (MESQUITA 2018: 201-2).

Mesquita encerra seu estudo procurando compreender o que ele chama de suspensão do negócio entre Freyre e o Estado Novo em 1945 - suspensão esta que, entretanto, manteve preservado o pacto entre regionalistas e centralistas, mesmo com o ocaso do regime. Este momento foi, de acordo com mesquita, um momento de transição política para Freyre: do antiliberalismo ao conservadorismo liberal (MESQUITA, 2018: 221-4). Nessa nova conjuntura, "Freyre passou a negociar a ideologia da contemporização inter-regional com a coalizão de forças que, a partir de então, dominou o poder depois do colapso do regime" (MESQUITA, 2018: 225).

A obra de Gilberto Freyre é vasta, deixando abetos muitos caminhos para pesquisadores que pretendam compreendê-la melhor e estudar o Brasil. Mesquita opta por se aprofundar na construção do regionalismo por este autor, fazendo a escolha inevitável de passar ao largo de uma série de temas que, como ele mesmo diz, foram melhor estudados em outros trabalhos. Sua abordagem não deixa de ser, porém, uma das mais valiosas contribuições para o melhor entendimento do pensamento social brasileiro.

\section{Referências}

ALBUQUERQUE JR., Durval Muniz de. A invenção do Nordeste e outras artes. Recife: Massananga, São Paulo: Cortez, 1999.

BOURDIEU, Pierre. A ilusão biográfica. In: AMADO, Janaína; Ferreira, Marieta de Moraes (Org.) Usos e abusos da história oral. 8. Edição. Rio de Janeiro: FGV, 2006. 
D'ANDREA, MOEMA SELMA. A tradição re(des)coberta: Gilberto Freyre e a literatura regionalista. Campinas: Editora UNICAMP, 1992.

FREYRE, Gilberto. Brazil: an interpretation. New York: Alfred A. Knofp, 1945.

FREYRE, Gilberto. Nordeste: aspectos da influência da canna sobre a vida e a paisagem do Nordeste do Brasil. Rio de Janeiro: José Olympio, 1937.

Mucambos do Nordeste: algumas notas sobre o tipo de casa popular mais primitivo do Nordeste do Brasil. Rio de Janeiro: Ministério da educação e Saúde, 1937.

Sobrados e mucambos: decadência do patriarcado rural e desenvolvimento urbano. 15. Edição. São Paulo: Global, 2004.

LACAPRA, Dominck. Repensar la historia intellectual y leer textos. In: PALTI, Elias José. "Giro linguistico" y historia intellectual. Buenos Aires: Universidad Nacional de Quilmes, 1998.

LOVEJOY, Arthur. The grat chain of being: The study of the History of an idea. 22 edição. Cambrige: Harvard University Press, 2001

MAIO, Marcos Chor. O Projeto Unesco e a agenda das ciências sociais no Brasil dos anos 40 e 50. Rev. bras. Ci. Soc., São Paulo, v. 14, n. 41, p. 141158, Out. $1999 . \quad$ Disponível em $<\mathrm{http} / / /$ www.scielo.br/scielo.php?script=sci_arttext\&pid=S010269091999000300009\&lng=en\&nrm=iso $>$. accesso em 11 Sept. 2020. https://doi.org/10.1590/S0102-69091999000300009.

MESQUITA, Gustavo. Gilberto Freyre e o Estado Novo: região, nação e modernidade. São Paulo: Global, 2018.

RAMOS, Arthur. "Os grandes problemas da Antropologia brasileira". Sociologia, X, 4: 213-226. 1948.

Recebido em: 10 de dezembro de 2019 Aceito em: 07 de julho de 2020 